\title{
DANCING IN THE RAIN: LIFE EXPERIENCE OF PREGNANT WOMEN WITH HIV INFECTION
}

\author{
Anggie Pradana Putri \\ Department of Maternal Nursing, Mamba'ul 'Ulum \\ Nursing Academy, Surakarta, Central Java
}

\begin{abstract}
Background: Pregnant women with HIV infection often face stigma, compromised health, and endangered lives of their babies. They need more attention physically, psychologically, and socially from surrounding people. On the other hand, there is a need for the women to have more self understanding about ways to struggle and survive. This study aimed to investigate life experience of pregnant women with HIV infection.

Subjects and Method: The researcher utilized qualitative study with phenomenology approach. Guided by a grand tour question, seven pregnant women who were HIV positive from Central Java, Yogyakarta and Jakarta, Indonesia, were interviewed. The themes emerged from the data were analyzed using Colaizzi method of data analysis.

Results: There were 121 formulated meanings captured by narration from the participants. These meanings were grouped based on their similarity. Three themes emerged from the analysis using Colaizzi analysis of qualitative data: 1) heavy burden, 2) source of strength and happiness, 3) readiness to rock the world.

Conclusion: Dancing in the rain emerged to be the main essence of life experience of pregnant women with HIV infection. Despite life with ambivalent feelings and unstoppable difficulties, they have to continue with their pregnancies and their lives. One of meaningful recommendations arising from this study is asking the community and government for collaboration to prevent stigmatization and discrimination against pregnant women with HIV infection.
\end{abstract}

Keywords: HIV infection, life experience, pregnant women, phenomenology.

Correspondence: Anggie P. Putri. Department of Maternal Nursing, Mamba'ul 'Ulum Nursing Academy, Surakarta, Central Java.

Email: anggie.pputri@gmail.com 